\title{
Perbandingan Algoritma SVM dan SVM Berbasis Particle Swarm Optimization Pada Klasifikasi Beras Mekongga
}

\author{
Emilia Ayu Wijayanti ${ }^{1}$, Tania Fatiah Rahmadanti ${ }^{2}$, Ultach Enri ${ }^{3}$ \\ ${ }^{1,2}$ Teknik Informatika, Fakultas Ilmu Komputer, Universitas Singaperbangsa Karawang \\ E-mail: *1emilia.ayu17089@student.unsika.ac.id,

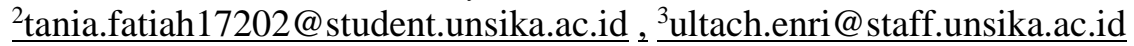

\begin{abstract}
Abstrak - Beras merupakan bahan makanan pokok paling penting di Indonesia. Terdapat berbagai macam jenis varietas yang ada, salah satunya ialah varietas Mekongga. Di karawang jenis beras Mekongga paling banyak diminati dan unggul dibandingkan dengan yang lainnya. Namun, jenis beras tersebut sering sekali tercampur dengan jenis beras lainnya dikarenakan terlalu banyak varietas yang ada dan berbagai macam permasalahan lain. Mengklasifikasikan varietas jenis beras dapat dilakukan guna mengidentifikasi jenis dari beras tersebut. Klasifikasi varietas jenis beras pada penelitian yang dilakukan dibagi menjadi 2 kelas yaitu Mekongga dan Bukan Mekongga. Metode yang digunakan pada penelitian ini ialah Support Vector Machine dan Particle Swarm Optimatizon. Metode Support Vector Machine dipilih karna metode ini pada dasarnya menangani klasifikasi dua kelas. Sedangkan metode Particle Swarm Optimatizon digunakan untuk mengoptimasikan tingkat akurasi dari metode Support Vector Machine. Kombinasi dua metode tersebut sangat baik digunakan dalam data klasifikasi karna dapat meningkatkan tingkat akurasi menjadi lebih baik. Tujuan penelitian ini ialah membandingkan tingkat akurasi dari 2 metode yang digunakan. Dari hasil penelitian klasifikasi beras mekongga dengan Support Vector Machine dihasilkan nilai akurasi sebesar $46.67 \%$ dengan AUC 0.475. sedangkan hasil Support Vector Machine (SVM) berbasis Particle Swarm Optimatizon (PSO) dapat membantu dalam meningkatkan klasifikasi beras mekongga ini dengan hasil akurasi 70.83\% dan AUC 0.671. Particle Swarm Optimatizon (PSO) pada algoritma yang sudah ada membantu meningkatkan nilai akurasi sebesar $24.16 \%$ dan dengan nilai AUC sebesar 0.916 dan termasuk kedalam excellent classification.
\end{abstract}

Kata Kunci-Beras Mekongga, Data Mining, Klasifikasi, PSO, SVM.

\begin{abstract}
The most staple food in Indonesia is rice. There are various types of varieties available, one of them is Inpari Mekongga variety. In Karawang, Mekongga rice type is the most popular and superior compared to others. However, this type of rice is often mixed with the other types because there are too many varieties and various other problems. Classifying varieties of rice types can be done to identify the types of rice. The classification of rice varieties in this research divided into 2 classes, Mekongga and not Mekongga. The method that used in the reserach is Support Vector Machine (SVM) and Particle Swarm Optimatizon (PSO). SVM method was chosen because it basically handles the classification of two classes. Meanwhile, PSO method used to optimize the accuracy level of the SVM method. Combination from the two methods is very well used in classification data because it can increase the level of accuracy better. The aim of this research is compare the accuracy from 2 methods that used. The results from research is mekongga rice classification with Support Vector Machine has accuracy value $46.67 \%$ and AUC value 0.475 . Meanwhile, using Support Vector Machine on Particle Swarm Optimization (PSO) may help improve the classification of this mekongga rice with accuracy value $70.83 \%$ and AUC value 0.671 . Particle Swarm Optimatizon (PSO) in the existing algorithm helps increase the accuracy value by $24.16 \%$ and with an AUC value of 0.916 and is included in the excellent classification.
\end{abstract}

Keywords - Classification, Data Mining,Mekongga Rice, PSO, SVM. 


\section{PENDAHULUAN}

Beras merupakan bulir yang berasal dari tanaman padi setelah melewati beberapa proses. Komponen teknologi yang paling ternama dan memiliki pengaruh yang besar pada peningkatan produksi serta penghasilan usaha tani adalah Varietas[7]. Indonesia menduduki peringkat ketiga tersebesar dalam memproduksi beras didunia. Berdasarkan kajian pangan bahan pokok yang dilakukan oleh Badan Pusat Statistik pada tahun 2017 (BPPT, 2017) menunjukan bahwa makanan beras nasional mencapai mencapai 29,13 juta ton atau sebanyak $111,58 \mathrm{~kg}$ per tahun pada tahun 2017 [9]. Lima provinsi penghasil beras terbanyak di Indonesia anatara lain Sumatra Selatan, Jawa Barat, Jawa Tengah, Jawa Timur serta Sulawesi Selatan[8].

Karawang terletak di provinsi Jawa Barat yang terkenal dengan lumbung padi nasional serta terdaftar sebagai produsen beras terbanyak kedua setelah Indramayu[11]. Padi memiliki berbagai varietas seperti Inpari (Inbrida Padi Sawah), Hipa (Hibrida Padi), Inpago (Inbrida Padi Gogo), Inpara (Inbrida Padi Rawa)[13]. Pada varietas yang telah disebutkan, terdapat berbagai jenis varietas lagi di dalamnya. Salah satunya yaitu Inpari memiliki jenis varietas Mekongga. Varietas Mekongga ini cukup unggul dan banyak diminati masyarakat[6]. Keunggulan pada varietas Mekongga ini terletak pada tanaman padi yang cukup tahan akan hama wereng dan penyakit hawar daun, serta beras yang menghasilkan kualitas baik dan tekstur nasi yang pulen[19]. Ciri pada varietas beras Mekongga ini yaitu memiliki bentuk yang ramping dan agak panjang[20]. Namun, terdapat permasalahan yang muncul, mayoritas petani kebanyakan menjual gabah kering panen langsung ke para penggilingan padi. Hal tersebut dapat menyebabkan tercampurnya berbagai macam varietas, ditambah adanya oknum yang melakukan pengoplosan beras[4]. Hal tersebut tentu saja dapat merugikan berbagai pihak. Oleh sebab itu, perlunya dilakukan cara dalam mengidentifikasi jenis beras agar jenis beras tidak dapat tercampur lagi dengan jenis lainnya. Salah satu cara untuk mengenali varietas beras yaitu dengan pengolahan citra digital. Pengolahan citra digital merupakan sebuah kegiatan mengolah citra dengan berbagai teknik menggunakan komputer[15]. Pengklasifikasian beras berdasarkan varietas jenisnya dengan menggunakan pengolahan citra dilakukan untuk dapat menangani permasalahan tersebut. Klasifikasi jenis beras tersebut dibagi menjadi 2 kelas, yaitu Mekongga dan Bukan Mekongga. Pengklasifikasin jenis beras Mekongga dan Bukan Mekongga ini penting dilakukan guna membantu masyarakat maupun pihak lainnya agar dapat mengetahui jenis beras Mekongga yang mereka beli meskipun jenis beras tersebut telah tercampur oleh jenis lainnya dan terhindar dari tindak penipuan yang dilakukan oknum tidak bertanggung jawab melalui pengoplosan beras.

Pada penelitian sebelumnya, telah dilakukan sebuah penelitian klasifikasi jenis varietas beras dengan melakukan pengolahan citra digital yang dilakukan oleh Ayyu[7]. Adapula Firmansyah pada penelitian sebelumnya menjelaskan bahwa algoritma Support Vector Machine (SVM) pada Perbandingan Klasifikasi SVM dan Decision Tree untuk Pemetaan Mangrove Berbasis Objek Menggunakan Citra Satelit Sentinel-2B di Gili Sulat, Lombok Timur memiliki hasil akurasi yang unggul sebesar 95\%[18]. Kemudian Amalia yang melakukan sebuah penelitian terkait penerapan metode SVM berbasis PSO, dalam penelitian tesebut menunjukan hasil yang menyatakan bahwa metode SVM berbasis PSO merupakan metode yang paling bagus untuk digunakan dalam data klasifikasi dan dapat meningkatkan nilai akurasi sebesar 99,6\% dalam penentuan kebangkrutan perusahaan di penelitian tersebut [10].

Tujuan penelitian ini ialah melakukan perbandingan hasil akurasi dalam mengklasifikasikan jenis varietas beras dengan menerapkan algoritma Support Vector Machine (SVM) berbasis Particle Swarm Optimatizon (PSO). Metode SVM dipilih karna metode ini pada dasarnya menangani klasifikasi dua kelas, namum juga memiliki kelemahan dalam pengolahan data dengan jumlah besar sehingga perlu dilakukan optimasi guna meningkatkan hasil akurasi yaitu dengan cara menggunakan PSO[10],[3],[14]. Kombinasi dua metode tersebut sangat baik digunakan dalam data klasifikasi karna dapat meningkatkan tingkat akurasi menjadi lebih baik[11].

\section{METODE PENELITIAN}

Penelitian ini menggunakan Dataset sebanyak 35 dari hasil ekstraksi citra. Metodologi CRISP-DM digunakan untuk menganalisis data tersebut. Pembuatan data mining dengan menggunakan Cross-Industry Standard Process for Data Mining (CRISP-DM) tersusun dari 6 fase, yaitu pemahaman bisnis (business understanding), pemahaman data (data understanding), 
pengolahan data (data preparation), pemodelan (modelling), evaluasi (evaluation), serta penyebaran (deployment)[8].

\subsection{Bussines Understanding}

Masalah tercampurnya berbagai macam jenis varietas beras banyak terjadi dipasaran yang dapat merugikan berbagai pihak. Tujuan penelitian dari data mining ini ialah membandingkan 2 algoritma yaitu Support Vector Machine (SVM) dan Support Vector Machine (SVM) berbasis Particle Swarm Optimization (PSO) pada klasifikasi jenis beras mekongga.

\subsection{Data Understanding}

Data yang digunakan berupa hasil ekstraksi citra yang diperoleh dari hasil akuisisi citra yang didapatkan seperti pada Gambar 1 berikut:
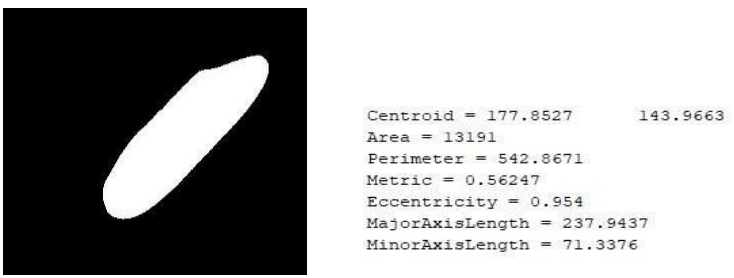

Gambar 1. Contoh Citra dengan Hasil Ekstraksi Ciri Bentuk.

Akusisi citra menghasilkan data ekstraksi citra sebanyak 35 records dan 7 atribut dengan keterangan seperti pada Tabel 1 berikut:

Tabel 1. Nilai Hasil Ekstraksi Citra

\begin{tabular}{ll}
\hline \multicolumn{1}{c}{ Atribut } & \multicolumn{1}{c}{ Keterangan } \\
\hline Area & Luas. \\
\hline Perimeter & Keliling. \\
\hline Metric & Perbangingan nilai antara keliling dan luas objek. \\
\hline Eccentricity & $\begin{array}{l}\text { Perbandingan nilai antara jarak foci ellips mayor dengan foci ellips } \\
\text { minor pada objek. }\end{array}$ \\
\hline $\begin{array}{l}\text { Major } \\
\text { Length }\end{array}$ & Major Axis. \\
\hline $\begin{array}{l}\text { Minor } \\
\text { Length }\end{array}$ & Axis \\
\hline $\begin{array}{l}\text { Beras } \\
\text { Mekongga }\end{array}$ & Minor Axis. \\
\hline
\end{tabular}

\subsection{Data Preparation}

Sebelum data dapat dilanjutkan untuk pemodelan data tersebut harus melalui proses atau langkah-langlah untuk membuat data mentah menjadi data yang dapat diolah pada proses data mining. Pada penelitian ini proses yang dilakukan adalah data tranformation. Data transformation adalah perubahan data yang ada menjadi data yang berkualitas[1]. Pada data ini dilakukan pembentukan label dan mengganti tipe data pada atribut yang akan dijadikan label.

\subsection{Modelling}

Dalam melakukan pemodelan untuk mencapai tujuan penelitian ini yaitu pengklafisikasian jenis varietas beras Mekongga dengan algoritma Support Vector Machine (SVM), kemudian guna meningkatkan nilai akurasi yang terbaik, digunakan algoritma Support Vector Machine (SVM) berbasis Particle Swarm Optimatizon (PSO).

\subsection{Evaluation}

Pada penelitian ini untuk menentukan evaluasi dengan menerapkan confusion matrix (accuracy) serta nilai AUC dari kurva ROC. 


\subsection{Deployment}

Proses knowledge presentation setelah tahap evaluasi dengan mempresentasikan model yang dihasilkan[5].

\section{HASIL DAN PEMBAHASAN}

\subsection{Proses Data Mining pada RapidMiner}

Penelitain ini membandingkan hasil klasifikasi beras mekongga dari 35 hasil ekstraksi citra. Data hasil ekstraksi citra ini terdiri dari 7 atribut. Pengklasifikasian beras mekongga dilakukan dengan menggunakan algoritma Support Vector Machine (SVM) dan Support Vector Machine (SVM) berbasis Particle Swarm Optimization (PSO). Maka dibutuhkan salah satu atribut tipe binominal, yang dimana pada dataset ini merubah tipe integer menjadi binominal pada atribut beras_mekongga. Atribut beras_mekongga ini berisini nilai 1 yaitu untuk "Ya" dan 0 yaitu untuk "Tidak". Pembagian data training serta testing di penelitian ini menggunakan Cross Validation. Pemodelan dalam membandingkan kedua 2 algoritma menggunakan Multyply.

Setelah dilakukan pemodelan dengan RapidMiner pada algoritma Support Vector Machine (SVM) dan Support Vector Machine (SVM) berbasis Particle Swarm Optimization (PSO) didpatkan nilai akurasi, precison, dan recall. Pada algoritma algoritma Support Vector Machine (SVM) didapatkan hasil akurasi sebesar $46.67 \%$, precision sebesar $45 \%$, dan recall sebesar $46.67 \%$. Sedangkan nilai AUC yang didapatkan pada kura ROC sebesar 0.475 yang termasuk kategori failure[2].

Tabel 2. Confusion Matrix SVM

\begin{tabular}{cccc}
\hline & True 1 & True 0 & Class Precision \\
\hline Pred. 1 & 7 & 8 & $46.67 \%$ \\
Pred. 0 & 11 & 9 & $45.00 \%$ \\
Class Recall & $38.89 \%$ & $52.94 \%$ & \\
\hline
\end{tabular}

Pada tabel 2 menunjukan hasil confusion matrix dengan algoritma Support Vector Machine (SVM). Berdasarkan tabel tersebut, diketahui dari data yang berjumlah 35 data, 7 data diprediksi 1 sesuai dengan prediksi yang dilakukan algoritma SVM, kemudian 8 data diprediksi 1 tetapi hasil prediksinya adalah 0 . Kemudian 9 data diprediksi 0 sesuai dengan dengan prediksi yang dilakukan algoritma SVM, dan 11 data diprediksi 0 tetapi ternyata hasil prediksinya 1.

Selanjutnya pengujian RapidMiner dengan algoritma algoritma Support Vector Machine (SVM) berbasis Particle Swarm Optimization (PSO) didapatkan hasil akurasi sebesar 70.83\%, precision sebesar $70.59 \%$, dan recall sebesar $68.33 \%$. Sedangkan nilai AUC yang didapatkan pada kura ROC sebesar 0.67 yang termasuk kategori poor classification[2].

Tabel 3. Confusion Matrix SVM berbasis PSO

\begin{tabular}{cccc}
\hline & True 1 & True 0 & Class Precision \\
\hline Pred. 1 & 13 & 5 & $72.22 \%$ \\
Pred. 0 & 5 & 12 & $70.59 \%$ \\
Class Recall & $72.22 \%$ & $70.59 \%$ & \\
\hline
\end{tabular}

Pada tabel 3 menunjukan hasil confusion matrix dengan algoritma Support Vector Machine (SVM) berbasis Particle Swarm Optimization (PSO). Berdasarkan tabel tersebut, diketahui dari data yang berjumlah 35 data, 13 data diprediksi 1 sesuai dengan prediksi yang dilakukan algoritma SVM berbasis PSO, kemudian 5 data diprediksi 1 tetapi hasil prediksinya adalah 0. Kemudian 12 data diprediksi 5 sesuai dengan dengan prediksi yang dilakukan algoritma SVM berbasis PSO, dan 11 data diprediksi 0 tetapi ternyata hasil prediksinya 1.

Dari pengguaan PSO pada algoritma Support Vector Machine diperoleh nilai weight pada setiap atribut. Pada Gambar 4 dapat dilihat atribut yang berpengaruh pada klasifikasi beras mekongga dengan nilai weight 1 yaitu perimeter, metric, dan minor axis length. 


\begin{tabular}{|l|l|}
\hline attribute & weight \\
\hline Area & 0 \\
\hline Perimeter & 1 \\
\hline Metric & 1 \\
\hline Eccentric... & 0 \\
\hline Major_Ax... & 0 \\
\hline Minor_Ax... & 1 \\
\hline
\end{tabular}

Gambar 4. Atribut Weight

\subsection{Analisa Hasil Evaluasi}

Hasil klasifikasi pada varietas beras Mekongga menggunakan algoritma Support Vector Machine (SVM) dapat dilihat pada Tabel 4. menghasilkan nilai akurasi sebesar $46.67 \%$ dengan nilai AUC sebesar 0.475 yang mana masih terdapat beberapa kesalahan yang dilakukan pada saat pengklasifikasian varietas beras dengan menggunakan algoritma ini. Algoritma Support Vector Machine (SVM) memiliki kelemahan dalam pengolahan data dengan jumlah besar sehingga perlu dilakukan optimasi guna meningkatkan hasil akurasi yaitu dengan cara menggunakan algoritma Particle Swarm Optimization (PSO). Algoritma Particle Swarm Optimization (PSO) digunakan karena kombinasi dua metode tersebut sangat baik digunakan dalam data klasifikasi karena dapat meningkatkan tingkat akurasi menjadi lebih baik[16]. Selain itu, dengan membandingkan kedua algoritma yaitu algoritma Support Vector Machine (SVM) dan Support Vector Machine (SVM) berbasis Particle Swarm Optimization (PSO) dapat dilihat perbandingan nilai akurasi keberhasilan yang dilakukan guna melihat seberapa baik algoritma tersebut dalam melakukan dalam pengkasifikasian jenis varietas beras.

Setelah dilakukan pemodelan dengan membandingkan algoritma Support Vector Machine (SVM) dan Support Vector Machine (SVM) berbasis Particle Swarm Optimization (PSO) dapat dibuktikan bahwa algoritma Support Vector Machine (SVM) berbasis Particle Swarm Optimization (PSO) memiliki tingkat klasifikasi lebih baik karena dapat meningkatkan nilai akurasi sebesar $24.16 \%$ dan meningkatkan nilai UAC sebesar 0.196. Dengan algoritma Support Vector Machine (SVM) yang hanya mendapatkan nilai akurasi sebesar 46.67\% dan nilai AUC 0.475. Sedangkan pada algoritma Support Vector Machine (SVM) berbasis Particle Swarm Optimization (PSO) mendapatkan nilai akurasi sebesar $70.83 \%$ dan dengan nilai AUC sebesar 0.671. Hasil Komparasi nilai akurasi dan AUC dapat dilihat pada Tabel 4.

Tabel 4. Komparasi nilai akurasi dan AUC

\begin{tabular}{cccc}
\hline & SVM & SVM berbasis & Peningkatan \\
& & PSO & \\
\hline Akurasi & $46.67 \%$ & $70.83 \%$ & $24.16 \%$ \\
AUC & 0.475 & 0.671 & 0.196 \\
\hline
\end{tabular}

\section{SIMPULAN}

Mengimplementasian algoritma dapat memberikan nilai akurasi yang lebih baik pada pengklasifikasian jenis varietas beras yang dilakukan. Nilai akurasi berfungsi untuk melihat seberapa akurat algoritma tersebut dalam melakukan klasifikasi jenis varietas beras. Hasil penelitian membuktikan bahwa algoritma Support Vector Machine (SVM) termasuk pada supervised learning yang dapat mengetahui dan membedakan jenis varietas beras[17]. Namun, algoritma ini memiliki kelemahan dalam pengolahan data dengan jumlah besar. Hasil pengklasifikasian beras mekongga dengan algoritma Support Vector Machine menghasilkan nilai akurasi sebesar $46.67 \%$ dengan nilai 
AUC 0.475 dan termasuk kedalam failure. Pengoptimasian dengan menggunakan algoritma Support Vector Machine berbasis Particle Swarm Optimatizon (PSO) berhasil meningkatkan tingat akurasi dalam pengkasifikasian. Dengan menggunakan algoritma Support Vector Machine berbasis Particle Swarm Optimatizon (PSO) didapatkan nilai akurasi sebesar 70.83\% dengan nilai AUC sebesar 0.671 yang mana hal tersebut menunjukan bahwa algoritma ini membantu dalam pengklasifikasian jenis varietas beras menjadi lebih baik dan akurat. Particle Swarm Optimatizon (PSO) pada algoritma yang sudah ada ini membantu meningkatkan nilai akurasi sebesar $24.16 \%$ dan dengan nilai AUC sebesar 0.916 dan termasuk kedalam excellent classification.

\section{SARAN}

Bersumber pada hasil penelitian serta kesimpulan, terdapat saran untuk bahan referensi pada penelitian berikutnya antara lain yaitu dataset yang digunakan dapat diperbanyak lagi dan juga jenis dari beras yang digunakan lebih banyak dalam pengujian variasinya. Selain itu, dapat diuji dengan menggunakan algoritma klasifikasi lainnya seperti Neural Network, Nä̈ve Baiyes, Decision Tree, K-NN, ataupun Logistic Regreesion.

\section{DAFTAR PUSTAKA}

[1] A. A. Ronaldi, N. Hunaifi, "Implementasi Data Mining Untuk Prediksi Penjualan Pestisida Pada CV Mitra Artha Sejati Menggunakan Algoritma Naive Bayes," Protektif (Eprosiding Teknik Informatika), 2021, 1(1), 250-257.

[2] A. K. Mohanty, S. Beberta, S. K. Lenka, "Classifying Benign and Malignant Mass using GLCM and GLRLM based Texture Features from Mammogram," International Journal of Engineering Research and Applications (IJERA), 2017, Vol. 1, hal. 687-693.

[3] A. S. Nugroho, A. B. Witarto, dan D. Handoko, "Support Vector Machine," Proceeding Indones, Sci. Meeiting Cent, Japan, 2003.

[4] A. Supriatna, "Analisis Sistem Pemasaran Gabah/Beras (Studi Kasus Petani Padi di Sumatra Utara)," SOCA: Jurnal Sosial Ekonomi Pertanian, 2005, Vol. 5, No. 1, p. 43920.

[5] Achyani, Yuni Eka, "Penerapan Metode Particle Swarm Optimization Pada Optimasi Prediksi Pemasaran Langsung," Jurnal Informatika, 2018, 1-11.

[6] Aristya, E. Vina, T. Taryono, "Pemuliaan Tanaman Partisipatif untuk Meningkatkan Peran Varietas Padi Unggul dalam Mendukung Swasembada Pangan Nasional," Agrotechnology Innovation (Agrinova) 2.1, 2019, 26-35.

[7] Ayyu Nurbait, 'Klasifikasi Pada Varietas Beras Mekongga Berdasarkan Citra Menggunakan Algoritma Support Vector Machine," Program Pasca Sarjana Ilmu Komputer, Univ. Singaperbangsa, Karawang, 2020.

[8] BPPT, "Badan Pengkajian Dan Penerapan Teknologi. In Luas Panen Dan Produksi Beras 2018," 2018. [Online]. Avaliable: https://www.bps.go.id/publication/2018/12/21/543c607a9ce62960d929060f/luas-panen-danproduksi-beras-di-indonesia-2018-hasil-kegiatan-pendataan-statistik-pertanian-tanamanpangan-terintegrasi-dengan-metode-kerangka-sampel-area-.html

[9] BPPT, “Kajian Konsumsi Bahan Pokok 2017," 2017. [Online]. Avaliable: https://www.bps.go.id/publication/kajian-konsumsi-bahan-pokok-tahun2017.html

[10] H. Amalia, A. F. Lestar, dan A. Puspita, "Penerapan Metode Svm Berbasis PSO Untuk Penentuan Kebangkrutan Perusahaan,” Jurnal Techno Nusa Mandiri, 2017, Vol. 14, No. 2, pp. 131-136.

[11] I. Chofyan, H.U. Rustan, dan A. Hariyanto, "Upaya mempertahankan Kabupaten Karawang sebagai lumbung padi nasional," 2015.

[12] I. Purnama, R. Saputra, A. Wibowo, "Implementasi Data Mining Menggunakan Crisp-Dm Pada Sistem Informasi Eksekutif Dinas Kelautan Dan Perikanan Provinsi Jawa Tengah," In Prosiding Seminar Nasional Ilmu Komputer UNDIP 2012, 2014.

[13] Ikhlas, Ariza, A. Abdullah, Y.P. Dwi, "Mesin Pembelajaran Ensemble Untuk Identifikasi Varietas Padi," Informatika Pertanian 29.2, 2020, 123-130. 
[14] K. P. Wijaya, M. A. Muslim, "Peningkatan Akurasi Pada Algoritma Support Vector Machine Dengan Penerapan Information Gain Untuk Mendiagnosa Chronic Kidney Disease", In Prosiding 3rd Seminar Nasional Ilmu Komputer, Semarang, Universitas Negeri Semarang, 2016.

[15] Kusumanto, R., Tompunu, N. Alan, "Pengolahan Citra Digital Untuk Mendeteksi Obyek Menggunakan Pengolahan Warna Model Normalisasi Rgb. Seminar Nasional Teknologi Informasi \& Komunikasi Terapan," 17(C), 2017, 329-332. https://doi.org/10.1016/S01661116(08)71924-1.

[16] Muhamad, Husin and others, "Optimasi Naïve Bayes Classifier Dengan Menggunakan Particle Swarm Optimization Pada Data Iris," Jurnal Teknologi Informasi dan Ilmu Komputer (JTIIK), p-ISSN, 2017, 2355-7699.

[17] Safitri, H. Pima, A. Anditya, N. R. Kurniawan, "Verifikasi Tanda Tangan Online Menggunakan Algoritma Genetika dan Support Vector Machine," eProceedings of Engineering 5.2, 2018

[18] S. Firmansyah, J. Gaol, S. B. Susilo, "Perbandingan Klasifikasi SVM dan Decision Tree untuk Pemetaan Mangrove Berbasis Objek Menggunakan 49 Citra Satelit Sentinel-2B di Gili Sulat Lombok Timur,” Ipb, 9(3), 2019, 746-757.

[19] W. Abbas, M. Riadi, dan I. Ridwan, "Respon tiga varietas padi (Oryza sativa L.) Pada Berbagai Sistem Tanam Legowo," Jurnal Penelitian dan Pengembangan Agrokompleks, 2018, pp. 4555.

[20] Z. A. Simanullang, H. Idris, A. A. Daradjat, Sahardi, "Mekongga", Balai Besar Penelitian Tanaman Padi Balitbangtan Kementrian Pertanian (BBPADI), 2018. [Online]. Avaliable: https://bbpadi.litbang.pertanian.go.id/index.php/varietas-padi/inbrida-padi-sawahinpari/mekongga. 